\title{
Peak Shaving in Power system using VSC based
}

\section{Electric spring}

\author{
Swathi Prabhu K ${ }^{1}$, Dr. Nagesh Prabhu ${ }^{2}$, Dinesh Shetty ${ }^{3}$ \\ Student, Department of Electrical and Electronics, NMAMIT, Karkala, India ${ }^{1}$ \\ Professor, Department of Electrical and Electronics, NMAM Institute of Technology, Karkala, India ${ }^{2}$ \\ Assistant Professor, Department of Electrical and Electronics, NMAMIT, Karkala, India ${ }^{3}$
}

\begin{abstract}
This paper mainly focuses on studying the effectiveness of the Electric Spring(ES) in regulating the source power when source voltage fed by unstable power source and balancing the load voltage during peak shaving. Due to renewable energy source which is intermittent in nature, the power generated at critical load will not meet the load demand. To meet the load demand Electric spring provides peak shaving of load voltage by balancing the source power. Thus, ES provides solution to the Power instability problem caused by such micro grids. In this project work, electric spring is implemented in conjunction with loads and demonstrates properties of electric spring.
\end{abstract}

Keywords: Energy supported electric spring, Reactive Power Compensator, Smart load, and peak shaving.

\section{INTRODUCTION}

With the use of renewable energy source, power generated by the power system should meet the load demand. Due to intermittent nature, it is difficult to determine the instantaneous total power generation. In order to achieve balanced power supply, new discipline of management strategies and control methodologies are proposed. The concept of Smartgrids based on various technologies like power electronics and tele-communication have been proposed as a optimistic solution. To cope with the uncertainty and variability of renewable energy sources, new methods for peak shaving of load voltage and power are required.

The peak shaving of load voltage is shown in this paper. When the critical load increases the voltage across critical load is maintained by using smart load. A new Electric spring concept is introduced wherein Non critical load (NC)and Electric Spring together forms the Smart load. Based on Hooke's law, reactive power is obtained by the electric spring so as to stabilize the critical loads line voltage. In order to control the critical load voltage a controllable voltage is injected by ES in series with NC load voltage.

In this paper Electric Spring is designed to maintain the source power constant. Constant supply of power is achieved by electric spring. The analysis is done for electric spring limits, electric spring principle and operating modes. Voltage support and suppression is checked using electric spring. The line power is made equal using electric springs and it behaves as a smart load along with non critical load. ES is designed using a full-bridge pwm inverter in series with noncritical load.

\section{BASIC PRINCIPLE OF ENERGY SUPPORTED ELECTRIC SPRING}

A. Principle of Electric Spring

According to the Hooke's law, the force generated by the mechanical spring is given as (1) and potential energy stored as(2).

$\mathrm{F}=-\mathrm{Ay}$

P. $E=\frac{1}{2}\left(\mathrm{Ay}^{2}\right)$

where $\mathrm{F}$ is the force vector, $\mathrm{A}$ is the spring constant and $\mathrm{y}$ is the displacement vector. An electric spring concept is introduced based on mechanical spring device that can be used for electric voltage reduction and boosting, electric energy storage and damping electric oscillation. Based on the force and potential energy equation generated by mechanical spring the physical relationship of the electric spring is given as:

$\mathrm{Q}_{\mathrm{A}}=\mathrm{C}_{\mathrm{f}} \mathrm{V}_{\mathrm{sp}}$ inductive mode

$Q_{A}=-C_{f} V_{s p}$ capacitive mode 
Where, $Q_{A}$ is the electric charge stored in the capacitor with capacitance $C_{f}$ and $V_{s p}$ is the electric potential difference across the capacitor. The equations (3) and (4) gives the voltage suppression and voltage support functions of electric spring which can be controlled by controlling the charge $Q_{A}$ stored in the capacitor. In a circuit electric spring is realized as a current controlled voltage source.

Thus, by controlling the current through capacitor can control the charge which in turn controls the capacitor voltage.

$Q_{A}=\int i_{C L} d t$

\section{B. Operation of Electric Spring}

An electric spring is a device, which is integrated in series with non-critical loads $\left(Z_{n c}\right)$ and forms the smart loads as shown in Fig.1. This smart load connection is utilized to maintain voltage $V_{c}$ at the critical load to the reference value $\mathrm{V}_{\mathrm{s}_{-} \text {ref }}$. The smart load comprising of non critical $\operatorname{load}\left(\mathrm{Z}_{\mathrm{nc}}\right)$ and electric spring (ES) are connected in parallel to the critical $\operatorname{load}\left(\mathrm{Z}_{\mathrm{c}}\right)$ and the voltage is $\mathrm{V}_{\mathrm{c}}$. For active power and reactive power compensation electric springs(ES) are utilized.

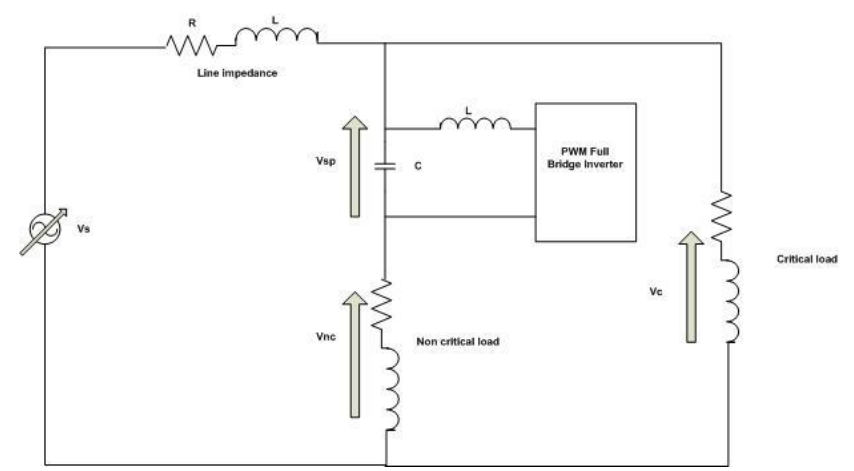

Fig.1 Block diagram of electric spring

By controlling an electric field in the capacitor, Operation of the electric spring can be controlled. This can be realized using closed loop control of mains voltage toV $\mathrm{V}_{s_{-} \text {ref }}$ as the reference. The energy stored in capacitor electric field is varied by keeping the value of $V_{s}(r m s)$ equal to an $V_{s_{-} \text {ref }}$, alternating EMF frequency can be generated with controllable magnitude across the capacitor gives the electric spring voltage $\left(\mathrm{V}_{\mathrm{sp}}\right)$. [1] If the vectors of $\mathrm{V}_{\mathrm{sp}}$ and $\mathrm{I}_{\mathrm{nc}}$ are perpendicular, then the ES is lossless similar to ideal mechanical spring for RPC. The current $I_{n c}$ can either leading the voltage $V_{\text {sp }}$ by $90^{\circ}$ or lagging $V_{\text {sp }}$ by $90^{\circ}$. This is illustrated in Fig.2.

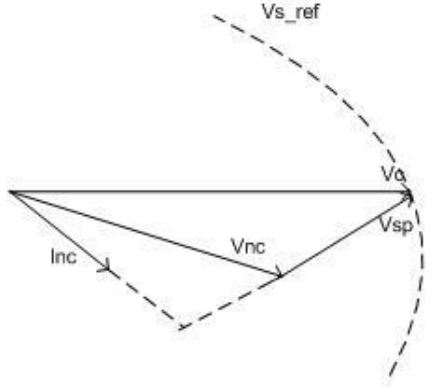

(a)

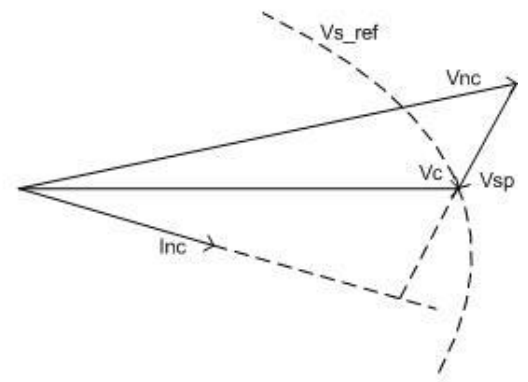

(b)

Fig.2 Phasor diagram of ES in(a)capacitive mode (b) inductive mode

If the electric spring voltage vector $V_{\mathrm{sp}}$ is perpendicular to the non critical load current $\mathrm{I}_{\mathrm{nc}}$, then the electric spring is considered as ideal device without any losses. For a resistive -inductive non critical load current $\mathrm{I}_{\mathrm{nc}}$ lags spring voltage $V_{\text {sp }}$ by $90^{\circ}$ and gives capacitive compensation and for a resistive -inductive non critical load current $\mathrm{I}_{\text {nc }}$ leads spring voltage $V_{\mathrm{sp}}$ by $90^{\circ}$ and givesinductive compensation. Vector equation for voltage in steady state condition can be written as $\mathrm{V}_{\mathrm{c}}=\mathrm{V}_{\mathrm{nc}}+\mathrm{V}_{\mathrm{sp}}$.

When the root-mean square voltage across the critical $\operatorname{load}\left(\mathrm{V}_{\mathrm{c}}\right)$ is less than the reference rms voltage $\mathrm{V}_{\mathrm{s}_{-} \text {ref }}(230 \mathrm{volts})$, then electric spring boosts the voltage instantaneously to the reference value, by adjusting voltage across the non critical load $\mathrm{V}_{\mathrm{nc}} \cdot[2]$ 
Vol. 4, Special Issue 2, April 2016

\section{CIRCUIT REALIZATION OF AN ELECTRIC SPRING}

Load can be categorized as two parts : a non critical load $\left(\mathrm{Z}_{\mathrm{nc}}\right)$ and a critical load $\left(\mathrm{Z}_{\mathrm{c}}\right)$. Non-critical loads can tolerate for some variations in power and voltage where as critical loads require constant voltage and power supply. This can be achieved by connecting ES in series with non critical load $\left(Z_{n c}\right)$. This arrangement is called "Smart Load". A VSC generates AC voltage from a DC voltage or vice versa. With a VSC magnitude, phase angle and the frequency of the output voltage can be controlled. AC waveform at the output is obtained by using four switches. The electric spring consists voltage source converter and low pass inductive-capacitive filter. A full bridge inverter is designed(Fig.3). VSC is implemented using MOSFETS. The power inverter has four freewheeling diodes which act as a diode rectifier. The PWM switching technique is adopted to switch the power MOSFET. The electric spring voltage is obtained across the filter capacitor.

SPWM reference signal is taken and compared with a triangle wave of $20 \mathrm{kHz}$ frequency generated using Repeating Sequence block.

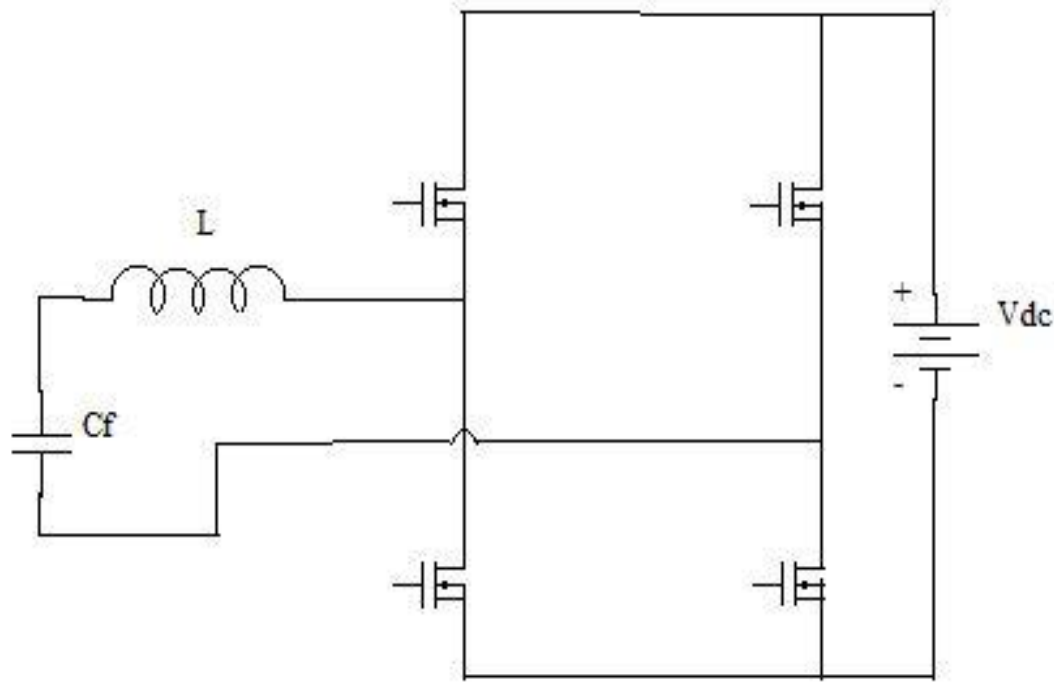

Fig.3 Full H-bridge inverter

Let $\mathrm{P}_{\mathrm{s}}$ be the source power which changes dynamically, then power-balance equation for system as shown in Fig. 1 is given as :

$$
\begin{aligned}
& P_{s}=\frac{V_{n c}{ }^{2}}{Z_{n c}}+\frac{V_{c}{ }^{2}}{Z_{c}} \\
& P_{s}=P_{n c}+P_{c}
\end{aligned}
$$

If power generated by the source $P_{s}$ cannot meet the full power at $P_{n c}$ and $P_{c}$, an ES will generate a voltage $V_{s p}$ to make the critical load voltage $V_{c}$ to reference voltage $V_{s_{-} \text {ref }}$.

$$
\mathrm{V}_{\mathrm{nc}}=\mathrm{V}_{\mathrm{s}}-\mathrm{V}_{\mathrm{sp}}
$$

From equation(8) the voltage across non-critical load is reduced which in turn reduces the power. Voltage across critical load increases and maintained to $\mathrm{V}_{\mathrm{s}_{-} \text {ref }}$. As a result of this the ES allows the load power consumption to automatically follow the power generation which requires a new control method by future power system with renewable energy sources. ES has certain limits like mechanical spring. Both real and reactive power is injected in future smart-grid, ES can be dynamically operated under neutral, capacitive or inductive mode with the objective of constant source power supply to the load during peak shaving.

\section{PRACTICAL EVALUATION}

In order to evaluate the performance and operating mode of electric spring, block diagram of the ES is modelled in MATLAB/SIMULINK as shown in Fig.4.The phase angle of the injected voltage $\left(\mathrm{V}_{\mathrm{sp}}\right)$ is $90^{\circ}$ with respect to the series non critical load current $\left(I_{n c}\right)$. A single-phase phase locked loop (PLL) is used to determine the phase angle of $I_{n c}$. The system was tested for under voltage and over voltage scenarios. The system specification is given in Table 1. 


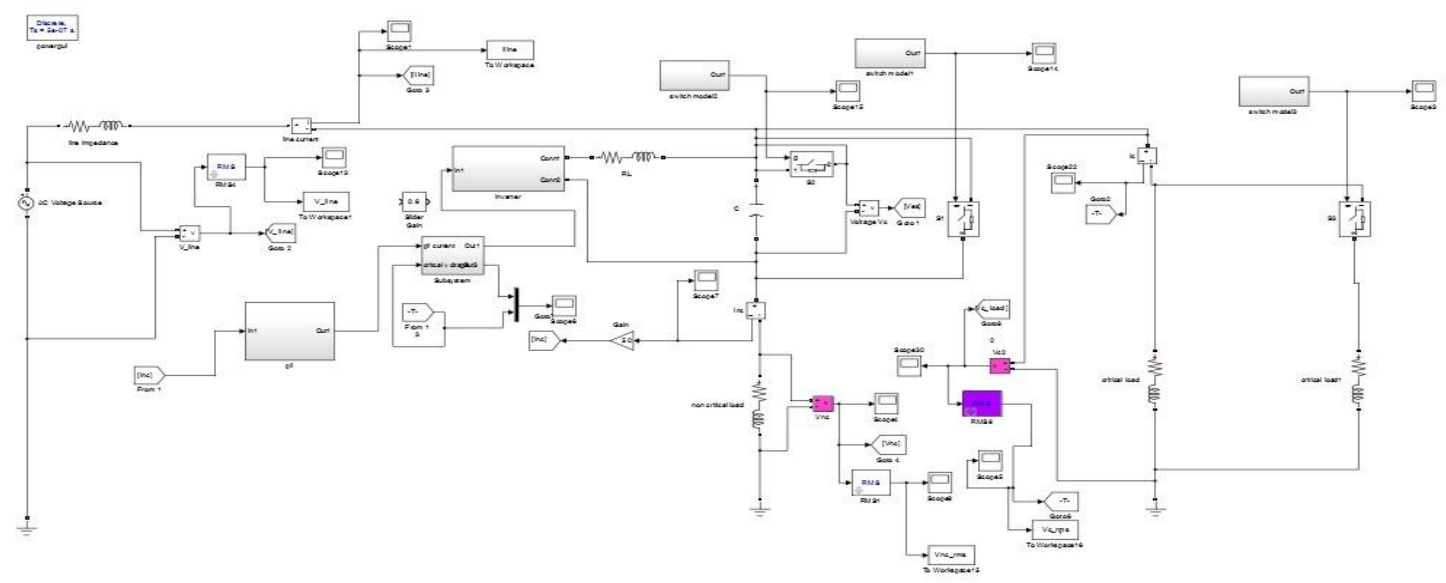

Fig.4Matlab simulation of ES

With the input voltage control method, the voltage error is fed to a controller and it generates a control signal to the SPWM . Synchronisation network gives the phase control signal to the PWM inverter. The PWM output voltage is filtered by LC filter to obtain sinusoidal wave. The phase control signals decides whether non-critical load current is leading or lagging by $90^{\circ} .[3]$ The conditions are $\mathrm{V}_{\mathrm{s}}=220 \mathrm{~V}(50 \mathrm{~Hz})$ and $\mathrm{Z}_{\mathrm{nc}}=7.01 \mathrm{ohm}$.

When the electric spring (ES) is activated and operated in capacitive mode noncritical load current leads ES voltage and when ES operated in inductive mode noncritical load lags ES voltage. This is shown in Fig.5

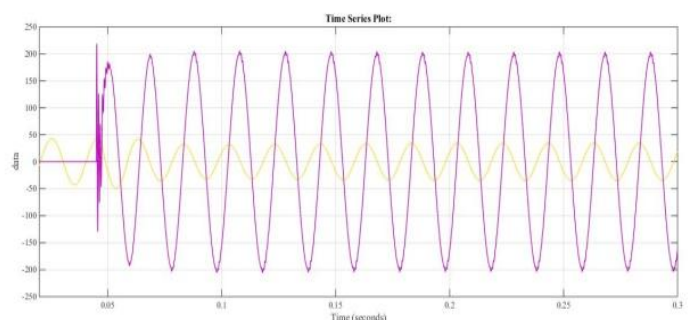

(a)

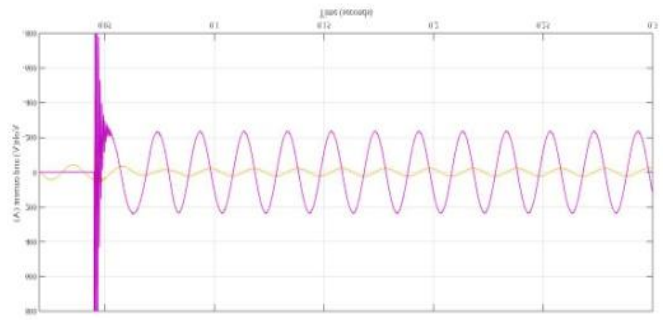

(b)

Fig.5(a)Non-critical load current leads ES voltage by $90^{\circ}$. $\quad$ (b)Non-critical load current lags ES voltage by $90^{\circ}$.

The renewable power which is intermittent in nature is generated by power inverter. The smart-load and critical $\operatorname{load}\left(\mathrm{Z}_{\mathrm{c}}\right)$ are connected across the source. Initially the electric spring is deactivated by closing the bypass switch $\mathrm{S}_{1}$ and activated when load gets increased. Fig.6 shows the rms values of non-critical load voltage and power and critical load voltage and power before and after the ES is activated. Before the activation of ES the voltage across the critical load and non critical load is $212.9 \mathrm{~V}$ and power supplied by source is $1.07 \mathrm{kw}$. When the load is increased, electric spring is activated and generates a positive voltage to support (increase) the source voltage. From practical measurement we can see the critical load voltage is increased to $219 \mathrm{~V}$ and noncritical load voltage is decreased to $172.5 \mathrm{~V}$. The power supplied by source is $9.7 \mathrm{KW}$. As active power increases the voltage across critical load increases and non-critical voltage reduces. This can be achieved by increasing modulation index.[5] To supply constant power supply from intermittent source to the load, the modulation index is decreased. This concept is illustrated in Fig.7.

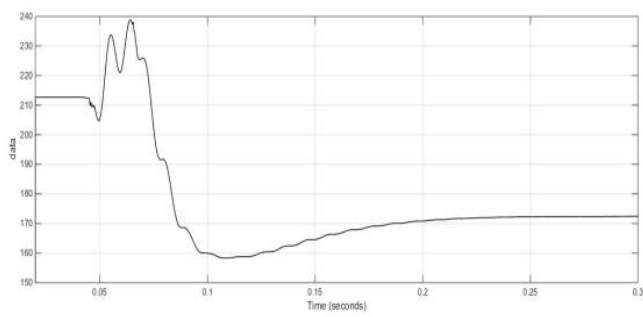

(a)

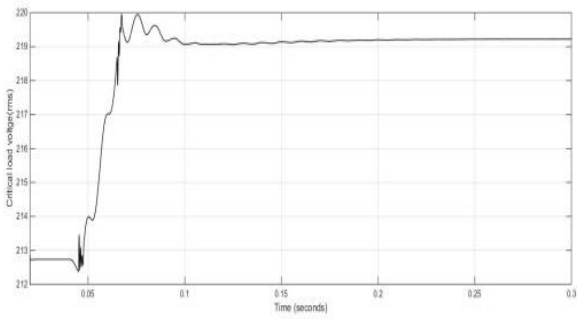

(b)

Fig.6 (a) Non-critical load voltage(rms). 


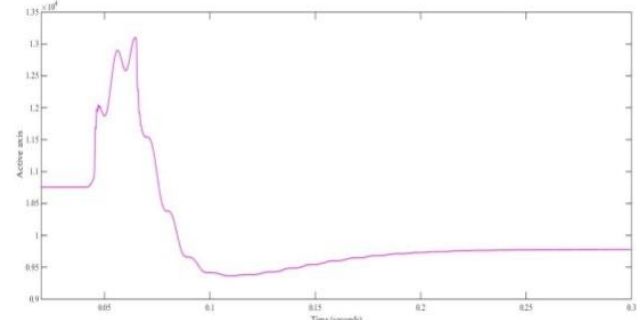

(a)

Fig.7 (a) Source power when $\mathrm{m}=0.975$

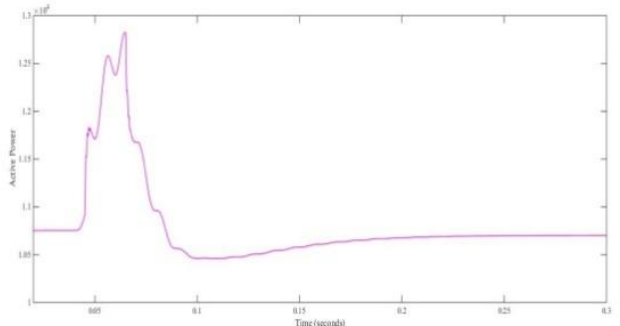

(b)

(b) Source power when $\mathrm{m}=0.77892$

TABLE I: SYSTEM SPECIFICATION

\begin{tabular}{|l|l|}
\hline Line impedance & $0.1 \mathrm{Ohms} 1.22 \mathrm{mH}$ \\
\hline Critical load & $11 \mathrm{Ohms}, 3.930 \mathrm{mH}$ \\
\hline Non-critical load & $7 \mathrm{Ohms}, 1.398 \mathrm{mH}$ \\
\hline Inverter & Single phase full H-Bridge Inverter \\
\hline DC voltage & 225 volts \\
\hline Switching-frequency & $20 \mathrm{kHz}$ \\
\hline $\begin{array}{l}\text { Filter specification: } \\
\text { Capacitance }\end{array}$ & $13.2 \mu \mathrm{F}$ \\
\hline Impedance & $0.10 \mathrm{Ohms}, 1.92 \mathrm{mH}$ \\
\hline
\end{tabular}

V. CONCLUSION

In capacitive mode of operation, the non critical load current lags electric spring voltage by $90^{\circ}$ which results in critical load voltage reduction. In inductive mode operation, the non critical load current leads electric spring voltage by $90^{\circ}$ which results in critical load voltage boosting. Non-critical load and Electric spring together forms a smart load by providing constant power supply to the critical load during peak shaving of critical load.

\section{ACKNOWLEDGMENT}

I would like to give my sincere gratitude to VISVESVARAYA TECHNOLOGICAL UNIVERSITY and NMAM INSTITUTE OF TECHNOLOGY for all support and encouragement.

\section{REFERENCES}

[1]. S. Y. R. Hui, C. K. Lee, and F.Wu, "Electric springs - A new smart grid technology," IEEE Trans. Smart Grid, vol. 3, no. 3, pp. 1552-1561, Sep. 2012.

[2]. Jayantika Soni, Krishnanand K R, S K Panda, “Load-side Demand Management in Buildings using Controlled Electric Springs"978-1-47994032-5/14/\$31.00,2014 IEEE.

[3]. Hooke's law - Britannica Encyclopedia [Online] Available:http://www.britannica.com/EBchecked/topic/271336/Hookes-law.

[4]. Shuo, Yan, Siew-Chong Tan, C. K. Lee, andS. Y. R. Hui. "Electric spring for power quality improvement", 2014 IEEE Applied Power Electronics Conference and Exposition -APEC 2014, 2014.

[5]. N.R. Chaudhuri, C.K. Lee, B. Chaudhuri, and S.Y.R. Hui, "Dynamic Model of Electric Spring, ” IEEE Transactions on Smart Grid, vol.5, no.5, pp. 2450-2458, 2014.

[6]. Chi Kwan Lee, , and Shu Yuen Hui."Reduction of Energy Storage Requirements in Future Smart Grid Using Electric Springs",IEEE Transactions on Smart Grid, 2013.

[7]. Chi Kwan Lee, , N. Ray Chaudhuri, Balako Chaudhuri, and S. Y. R. Hui. "Droop Control of Distributed Electric Springs for Stabilizing Future Power Grid", IEEE Transactions on Smart Grid, 2013. 